\title{
Perspectivas dos terapeutas ocupacionais sobre sua inserçáo nos Núcleos de Apoio à Saúde da Família (NASF) de Fortaleza, CE
}

\author{
Fernanda Reis ${ }^{\mathrm{a}}$, Ana Cléa Veras Camurça Vieira ${ }^{\mathrm{b}}$ \\ aTerapeuta ocupacional, Mestre em Saúde Pública, Universidade Federal do Ceará, Fortaleza - CE, Brasil \\ ${ }^{\text {b} T e r a p e u t a ~ o c u p a c i o n a l, ~ M e s t r e ~ e m ~ E d u c a c ̧ a ̃ o ~ e m ~ S a u ́ d e, ~ U n i v e r s i d a d e ~ d e ~ F o r t a l e z a ~-~ U N I F O R, ~ F o r t a l e z a, ~ C E, ~ B r a s i l ~}$
}

\begin{abstract}
Resumo: Os Núcleos de Apoio à Saúde da Família (NASF) configuram-se hoje como um novo cenário de atuação dos terapeutas ocupacionais inseridos na Atenção Primária à Saúde. Com o objetivo de compreender essa nova inserção, realizamos um estudo descritivo de abordagem qualitativa. Por meio de um grupo focal, obtivemos as informações sobre o tema com 13 terapeutas ocupacionais que atuavam nos NASF no município de Fortaleza, Ceará. O material obtido foi categorizado mediante análise temática e interpretado à luz dos referenciais teóricos da saúde coletiva e da Terapia Ocupacional. Os resultados e discussões convergiram para as categorias sobre: (1) inserção dos terapeutas ocupacionais no NASF e (2) condições de trabalho: um espaço de fragilidades e superação. Os achados apontam a necessidade de estabelecer uma agenda comum entre os profissionais do NASF e os profissionais das Equipes de Saúde da Família, as dificuldades do estabelecimento do vínculo na relação entre apoiador e apoiado na produção do trabalho em saúde, a precarização do trabalho e a escassez de materiais. O encontro desses profissionais foi potencializador de reflexões sobre os processos de trabalho e de trocas de experiências que possibilitaram sensibilização para novas perspectivas da categoria na Atenção Primária e para a necessidade de iniciativas de publicização da atuação dos terapeutas ocupacionais nesse contexto.
\end{abstract}

Palavras-chave: Terapia Ocupacional, Atenção Primária à Saúde, Condições de Trabalho.

\section{Insertion of occupational therapists in the support centers for family health of Fortaleza}

\begin{abstract}
Today, Family Health Support Centers (FHSC) characterize new environment for the activity of occupational therapists in Primary Health Care. Aiming to understand this new insertion we carried out a descriptive study of qualitative nature. Through a focus group, we obtained data on the subject from 13 occupation therapists that have worked in FHSCs in the municipality of Fortaleza, Ceará state, Brazil. The material obtained was categorized by thematic analysis and interpreted based on collective health and occupation therapy frameworks. The results and discussion converged to the categories of (1) Insertion of occupational therapists in the FHSNs studied, and (2) Working conditions: a place characterized by fragilities and overcoming. Our findings point to the need to establish a common agenda between FHSN professionals and Family Health Strategy teams; difficulties in establishing bonds between the supporters and the supported in the work process; working precariousness and material shortage. The encounter of such professionals potentiated reflections about the working processes and the exchange of experiences, raising awareness to new perspectives for occupational therapy in Primary Health Care and to the need to make these professionals' performances in this specific context more public.
\end{abstract}

Keywords: Occupational Therapy, Primary Health Care, Working Conditions.

Autor para correspondência: Fernanda Reis, Secretaria de Saúde do Estado da Bahia, Av. Luis Vianna Filho, 400, Sala 210-A, Secretaria da Saúde, Centro Administrativo da Bahia - CAB, CEP 41745-900, Salvador, BA. e-mail: fernandareis_to@yahoo.com.br Recebido em 12/9/2011; Revisão em 9/11/2012; Aceito em 18/12/2012. 


\section{Introdução}

Este estudo propõe-se a compreender a inserção dos terapeutas ocupacionais na Estratégia de Saúde da Família (ESF) de Fortaleza, Ceará, por meio dos Núcleos de Apoio à Saúde da Família (NASF).

A ESF configura-se como a principal aposta para a reorganização e a consolidação de um modelo alternativo de saúde no país, em contraposição aos modelos assistenciais ainda hegemônicos: o médico assistencial privatista, conhecido como de "procedimento-centrado", e o sanitarista (PAIM, 2003).

$\mathrm{O}$ trabalho na ESF centrou-se inicialmente em equipes multiprofissionais, também conhecidas como "equipes mínimas", compostas por um médico, um enfermeiro, um auxiliar de enfermagem e agentes comunitários de saúde (ACS), podendo contar também com equipes de saúde bucal compostas por cirurgiáo-dentista e auxiliar de saúde bucal. $\mathrm{O}$ objetivo dessas equipes é oferecer cuidado integral à saúde das famílias e comunidades situadas em seu território adscrito.

Segundo Franco e Merhy (2003), a estratégia apostou em uma mudança do desenho sob o qual opera o serviço, mas não nos afazeres do cotidiano de cada profissional, que em última instância é quem define o perfil da assistência. Assim, apontam que a implantação da ESF não garantiu a ruptura com a dinâmica médica, centrada no modelo hegemônico.

Compreendendo as limitações das Equipes de Saúde da Família (EqSF) em oferecer atenção integral à saúde nos seus territórios de abrangência, o Ministério da Saúde criou os Núcleos de Apoio à Saúde da Família (NASF), com o objetivo de apoiar a inserção da ESF na rede de serviços e ampliar açóes da Atenção Primária à Saúde no Brasil (BRASIL, 2009).

O NASF é composto de nove áreas estratégicas: saúde mental, saúde da criança/do adolescente e do jovem; reabilitaçáo/saúde integral da pessoa idosa; alimentação e nutrição; serviço social; saúde da mulher; assistência farmacêutica; atividade física/práticas corporais; práticas integrativas e complementares e deve ser constituído por uma equipe na qual profissionais de diferentes áreas de conhecimento atuem em conjunto com os profissionais das EqSF.

Para isso, a ESF passa a contar, então, com a presença de equipes multiprofissionais que podem ser compostas pelas seguintes categorias profissionais: médicos especialistas em pediatria, ginecologia/ obstetrícia, geriatria, psiquiatria, homeopatia, clínica médica, acupuntura e médico do trabalho; arte-educador; assistente social; educador físico; farmacêutico; fisioterapeuta; fonoaudiólogo; nutricionista; médico veterinário; psicólogo; terapeuta ocupacional e profissional de saúde sanitarista (BRASIL, 2011b).

A perspectiva de atuação das equipes de apoio na saúde é nova. As primeiras experiências no país foram iniciadas em Campinas, sendo chamadas de equipes matriciais (CAMPOS, 1999). O apoio oferecido pelo NASF objetiva assegurar uma retaguarda especializada (assistencial e técnico-pedagógica) a equipes encarregadas da atenção à saúde nos territórios, não se constituindo assim como porta de entrada do sistema (BRASIL, 2009).

A Portaria GM/MS no 154/2008 (BRASIL, 2008) propóe que o profissional terapeuta ocupacional seja um profissional de apoio na área de saúde mental e recomenda-se que cada NASF conte com pelo menos um profissional dessa área, que poderá ser também um psicólogo ou psiquiatra, tendo em vista a magnitude epidemiológica dos transtornos mentais.

Tal definição proposta pelo ministério vem suscitando amplas discussóes nos espaços de construção científica da profissão, de forma que muitos profissionais alegam a não consideraçáo do terapeuta ocupacional como apoiador nas questóes específicas de reabilitação. Além disso, outros aspectos tem sido levantados pelos profissionais que hoje se inserem no NASF, como a grande demanda encontrada, a falta de materiais, os recursos humanos e o convívio com as diferenças sociais (JARDIM; AFONSO; PIRES, 2008).

Os princípios e diretrizes do NASF fazem referência a conceitos e pressupostos que devem ser incorporados na atenção desses profissionais e devem nortear seus processos de trabalho como, por exemplo: coordenação do cuidado, apoio matricial, interdisciplinaridade, educação permanente, humanização, promoção da saúde, participação social, vínculo, clínica ampliada, entre outros. Esses constituem os principais conteúdos do campo da saúde coletiva brasileira e deverão ser operados em trabalho vivo (MERHY, 1998), no cotidiano das equipes.

Os apontamentos colocados pelos documentos oficiais do Ministério da Saúde para a estruturação do NASF são semelhantes aos que norteiam a própria Estratégia de Saúde da Família, acrescidos de referenciais atuais da área e das especificidades e particularidades da condiçáo de apoiador nesse contexto.

Assim, o desafio colocado para a prática profissional do NASF não é pequeno, pois representa o fortalecimento de um modelo alternativo e contra-hegemônico a partir da instauração de novos processos de trabalho e de açôes transformadoras. 


\section{Terapia Ocupacional: histórico de inserção no SUS}

A compreensão da conjuntura histórica e política na qual o terapeuta ocupacional está inserido no Sistema Único de Saúde faz-se necessária, bem como a construção histórica da categoria nesse campo, que também está intimamente relacionada a um conjunto de relaçóes e valores ideológicos da formação social em que essa formação se inscreve (CAVALCANTE; TAVARES; BEZERRA, 2008).

Tradicionalmente, a inserção da Terapia Ocupacional no SUS ocorreu a partir da alta e média complexidade, principalmente no campo da reabilitação (BEIRÃO; ALVES, 2010). A formação do terapeuta ocupacional ao longo da história também foi centrada no modelo biomédico - herança norte-americana do Movimento Internacional de Reabilitação - e na construção de áreas e especialidades de atuaçáo.

A aproximação da categoria das discussóes da promoção da saúde e as reflexôes acerca da determinação social da saúde ocorreram por volta do final dos anos 1970, particularmente com a participação de terapeutas ocupacionais no movimento de reforma sanitária. Essa preocupação evidenciou os limites da intervenção terapêutica, que não poderiam ser definidos apenas no interior da própria profissão, e que as açôes desses profissionais não ocorriam isoladamente do contexto social (BARROS; GHIRARDI; LOPES, 1999).

Estudos realizados por Malfitano e Ferreira (2011) evidenciam que ao ocupar novos espaços de ação, a profissão foi abandonando o seu histórico vinculado às ações assistencialistas e caritativas e passou a contribuir na construção do SUS, ampliando assim o desenvolvimento da categoria.

Torna-se importante destacar o movimento de vanguarda do município de Sáo Paulo na incorporação de terapeutas ocupacionais ao serviço público, especialmente na Atenção Primária à Saúde. Desde o final da década de 1980 e início de 1990, o município incluiu terapeutas ocupacionais nas Unidades Básicas de Saúde (OLIVER; BARROS; LOPES, 2005; HO; OLIVER, 2005).

Tal inserção provocou a ampliação das possibilidades de atuação da profissáo, pois os profissionais, diante da complexidade das situaçóes assistenciais encontradas no campo, tiveram de lançar mão de outros referenciais, além daqueles do campo biomédico, como a reorientação de iniciativas e a adoção de estratégias mais aproximadas ao contexto sociocultural da população (HO; OLIVER, 2005).
Pode-se enfatizar nessa assertiva a importância do contexto a partir dos determinantes sociais de saúde, que estão diretamente ligados ao conjunto de problemas que se relacionam com as condições de vida, com as formas de desenvolvimento das políticas no país e com a própria organizaçáo da sociedade brasileira. São, portanto, as condiçôes sociais em que as pessoas vivem e trabalham ou as características sociais dentro das quais a vida transcorre (PAIM, 2006).

Nessa perspectiva, o objeto de estudo da Terapia Ocupacional - a atividade humana, por meio da qual o "homem se percebe construtor do mundo e de si" (JORGE, 2004, p. 18) - amplia-se. O enfoque o profissional deixa de ser apenas o indivíduo e suas atividades e passa a ser o fazer humano imerso no contexto dos determinantes sociais de saúde. Assim, a atividade é considerada também como um instrumento de emancipação dos sujeitos, alimentado pela dimensão sociopolítica, cultural e afetiva de pessoas, grupos e comunidades (BARROS; LOPES; GALHEIGO, 2007).

Essa dimensão teórica sobre a atuação do terapeuta ocupacional está explícita nos documentos que reúnem as definiçóes da profissão de Terapia Ocupacional, no Brasil, na proposição da Universidade de São Paulo, e, no mundo, pela Federação Mundial de Terapeutas Ocupacionais (WORLD..., 2003), conceituando-a como campo de conhecimento e de intervenção em saúde, educação e na esfera social, ao reunir tecnologias orientadas para a emancipaçáo e a autonomia das pessoas que, por razóes ligadas a problemática específica - físicas, sensoriais, mentais, psicológicas e/ou sociais -, apresentem, temporaria ou permanentemente, dificuldades na inserção e participação na vida social. Tais intervençóes dimensionam-se pelo uso da atividade, elemento centralizador e orientador, na construção complexa e contextualizada do processo terapêutico.

Nesse sentido, acreditamos que o amadurecimento da profissão no campo da Atenção Primária, incrementado principalmente pela inserção de muitos profissionais no NASF, gerará um importante movimento de produção de novos saberes e práticas para a fundamentação da Terapia Ocupacional nesse contexto.

\section{Cenário da Estratégia Saúde da Família em Fortaleza, CE}

A cidade de Fortaleza está localizada no estado do Ceará, no Nordeste do Brasil, e possui 2.447.409 habitantes (INSTITUTO..., 2010). É dividida 
administrativamente em seis secretarias executivas regionais (SER) e conta com o trabalho de $265 \mathrm{EqSF}$ e 22 equipes de NASF (BRASIL, 2011a).

A implantação da ESF em Fortaleza teve uma rápida expansão, saindo de um patamar de 77 equipes, em 2005, para 234, em 2006. Frota (2008), em seu estudo, apontou as dificuldades na implantação dos processos de trabalho na ESF de Fortaleza, dentre as quais podemos destacar a coexistência de modelos de atençáo territorial versus assistencial privatista e curativista; um cenário urbano sobrecarregando sua implementação; a violência urbana; e a baixa integração entre os profissionais das EqSF e os profissionais veteranos da Atenção Básica.

Nesse cenário inseriram-se, em julho de 2009, os NASF no município de Fortaleza, com 19 equipes compostas por 8 categorias profissionais, dentre elas os terapeutas ocupacionais presentes em todas as SER da cidade (BRASIL, 2011a; FORTALEZA, 2009).

$\mathrm{Na}$ época da realização da pesquisa, a cidade possuía 22 terapeutas ocupacionais oferecendo apoio específico às Equipes de Saúde da Família e, diante do cenário e das reflexôes produzidas acerca da inserção da categoria no SUS, nos questionamos: Como se deu a inserção dos terapeutas ocupacionais no cenário da Atenção Primária à Saúde de Fortaleza? Quais os desafios enfrentados pelos profissionais nesse contexto?

Objetivando responder a esses questionamentos, este estudo realizou uma aproximação com o novo cenário de atuação da Terapia Ocupacional, em busca da compreensão de como vem se dando a inserção da categoria nos NASF. Estudos exploratórios iniciais acerca das experiências que vêm se estabelecendo no país são necessários na atual conjuntura, pois propóem reflexões que auxiliam na construção de novas perspectivas de trabalho, bem como contribuem para suscitar discussóes no campo disciplinar e interdisciplinar, táo necessárias para a consolidação da categoria neste contexto.

\section{Metodologia}

Trata-se de um estudo descritivo de abordagem qualitativa. Tal opção metodológica justifica-se pela complexidade dos processos e fenômenos que foram estudados, os quais não puderam ser quantificados (MINAYO, 2004), pois envolveram a prática de sujeitos inseridos em um contexto histórico e social (MERCADO; BOSI, 2004).

Para coleta de dados foi utilizada a técnica de grupo focal tendo em vista o benefício da "[...] interação grupal para a produção de dados e insights que seriam menos acessíveis fora do contexto interacional" (GOMES; TELLES; ROBALLO, 2009, p. 857).

A utilização do grupo focal configurou-se como um dispositivo muito rico, pois além de possibilitar o conhecimento do tema Terapia Ocupacional no NASF em Fortaleza, a partir da realidade, significados e perspectivas dos próprios trabalhadores, foi possível proporcionar também a troca de experiência entre os profissionais, bem como a reflexão acerca dos seus processos de trabalho.

Foi realizada uma sessão de grupo focal em março de 2011, da qual participaram 13 dos 22 terapeutas ocupacionais que atuavam nos NASF de Fortaleza no período da pesquisa. O convite para a participação foi realizado por meio de contato telefônico e a reunião do grupo focal aconteceu na sede do Conselho Regional de Fisioterapia e Terapia Ocupacional da $6^{a}$ Região, por ser um local conhecido por todos os profissionais e possuir instalaçóes adequadas para a sua realização.

O encontro foi mediado pelo pesquisador, que utilizou um roteiro de questóes para nortear a condução do grupo focal. Além disso, contou com a colaboração de dois observadores, que ficaram responsáveis pelo registro dos aspectos relacionados à comunicação não verbal dos sujeitos no espaço de pesquisa como, por exemplo, o registro da interaçáo entre os participantes e o interesse/desinteresse demonstrado no grupo.

Com vistas a obter informaçóes acerca do perfil desses profissionais, utilizamos também um questionário, como técnica complementar ao grupo focal, o qual continha questôes sobre idade, sexo, formação, tempo de ingresso no NASF e experiências profissionais prévias.

A maioria dos sujeitos da pesquisa atuava anteriormente no serviço privado, de forma exclusiva ou concomitantemente com um vínculo no setor público ou no terceiro setor; e possuía de dois a seis anos de formados. Quase todos possuíam especialização, com exceção de um participante, sendo a maior parte das formaçóes situada nas áreas de saúde do idoso, psicomotricidade e áreas afins da saúde coletiva.

Todos os profissionais foram contratados por uma empresa terceirizada de recursos humanos e o critério de seleção foi por análise curricular. A maioria dos participantes tinha, em média, 2 anos de atuação no NASF, sendo que uma profissional havia sido contratada há 5 meses. Grande parte referiu ter participado de cursos oferecidos pela prefeitura depois que ingressou no NASF. 
As informaçóes obtidas no grupo focal foram gravadas e, em seguida, transcritas, categorizadas por meio de análise temática (MINAYO, 2004) e analisadas à luz dos referenciais teóricos da saúde coletiva e da Terapia Ocupacional.

A partir da análise do material produzido no espaço de encontros e diálogo dos terapeutas ocupacionais dos NASF, as informaçóes obtidas foram categorizadas em (1) Inserção dos terapeutas ocupacionais no Núcleo de Apoio à Saúde da Família em Fortaleza e (2) as Condiçóes de trabalho: um espaço de fragilidades e superação.

Quanto aos aspectos éticos, a pesquisa cumpriu as diretrizes e normas estabelecidas pela Resolução 196/96 do Conselho Nacional de Saúde (BRASIL, 1996) para pesquisas envolvendo seres humanos e a obtenção dos dados só teve início após a aprovaçáo do estudo pelo Comitê de Ética da Universidade de Fortaleza - processo n. 342/2010.

\section{Resultados e discussão}

\subsection{Inserção dos terapeutas ocupacionais no Núcleo de Apoio à Saúde da Família em Fortaleza}

Nos relatos sobre o processo de construção "inaugural" da categoria no universo da Atenção Primária em Saúde e na estratégia de apoio, os profissionais enfatizaram a inserção das equipes do NASF na ESF em Fortaleza, bem como os desafios que encontraram nesse processo.

$\mathrm{Na}$ avaliação dos profissionais, o processo de inserção foi permeado por dificuldades inerentes à implantação de uma nova política como, por exemplo, o desconhecimento dos atores da ESF do funcionamento do trabalho nessa nova lógica. Somado a isso, existiam debilidades que se referiam a aspectos normativos, retaguarda administrativa e condiçóes de trabalho. Contudo, os profissionais apontam avanços e relatam sobre as estratégias utilizadas para a consolidação do trabalho.

No início da inserção, os profissionais afirmam que realizaram apresentaçóes para os funcionários de cada Centro de Saúde da Família (CSF) nos quais estavam inseridos, com o objetivo de apresentar o NASF, as categorias profissionais da equipe e as possibilidades de trabalho conjunto com a equipe mínima. Não obstante, apontam que essa estratégia inicial não foi suficiente, tendo em vista a variedade de elementos que interpóem-se a essa aproximação, como veremos a seguir.
A quantidade de equipes apoiadas e o número de CSF de responsabilidade de cada equipe de NASF foi colocada como um primeiro obstáculo. $\mathrm{Na}$ época da realização da pesquisa, o Ministério da Saúde estabelecia que cada NASF 1 deveria apoiar de 8 a 15 EqSF e a Prefeitura de Fortaleza orientava que NASF deveria estar vinculado à EqSF completas. Entretanto, em alguns CSF que atuavam, os profissionais também ofereciam apoio àquelas equipes incompletas, tendo em vista as necessidades que apresentavam. Dessa forma, os profissionais sentiam-se sobrecarregados nas suas atuações.

Além disso, por atuarem em muitos CSF - alguns atuam em cinco unidades - os profissionais alegam que é difícil estabelecer uma agenda comum entre NASF e EqSF. Além da impossibilidade de estar presente em determinadas atividades dos CSF, os participantes afirmam que, quando presentes, os profissionais das EqSF apresentam uma demanda excessiva de atendimentos para realizar, o que dificulta a possibilidade de atuação compartilhada.

Essa dificuldade foi também discutida por Lancman e Barros (2011) na realidade da cidade de São Paulo. As autoras mencionam que isso ocorre pelo descompasso existente nas orientaçóes previstas para a atuação das equipes, já que as do NASF recebem orientação de atuaçáo em torno de reuniôes, grupos e outras atividades compartilhadas e as EqSF são orientadas a realizar um elevado número de consultas individuais.

O resultado é a dificuldade de implementação de um dos principais elementos na relação entre apoiador e apoiado na produção do trabalho em saúde: o vínculo. Sobre a importância do vínculo nas produções humanas, Marx e Engels (1987, p. 69) contribuem com a afirmação:
Os homens não agem apenas sobre a natureza, mas também uns sobre os outros. Eles somente produzem colaborando de uma determinada forma e trocando entre si suas atividades. Para produzirem, contraem determinados vínculos e relações mútuas e somente dentro desses vínculos e relaçôes sociais é que se opera sua ação sobre a natureza, isto é, se realiza a produção.

Andrade et al. (2012, p. 28) apontam que as implicaçóes dessa realidade são grandes frente ao que é idealizado para o âmbito do trabalho nos NASF. Esses autores apontam que

[...] o discurso e a ação são antagônicos, uma vez que há carência em termos de compartilhamento de responsabilidades, trabalho interdisciplinar efetivo e desenvolvimento de projetos terapêuticos conjuntos. 
A partir desse entendimento, o processo de aproximação e inserção é visto como sistemático e desafiador. Os participantes descrevem que nos primeiros momentos as dificuldades eram muito maiores, pois os próprios profissionais das equipes do NASF não sabiam ao certo qual era o seu papel e não sentiam segurança suficiente para afirmar sobre suas competências, ferramentas e açóes, como podemos evidenciar na fala a seguir: "É uma luta diária, foi se construindo...".

Os atuais estudos realizados sobre os NASF no Brasil reforçam esses achados e mostram a mesma realidade. Lancman e Barros (2011, p. 267), que realizaram pesquisa em Sáo Paulo, confirmam os estudos realizados e apontam que a

[...] implantaçáo dos NASF tem acontecido de maneira irregular, sem processos de capacitaçáo apropriados, com má definição de papéis, com processos de trabalho por vezes conflituosos com as equipes.

As autoras argumentam ainda que o documento norteador do NASF define de forma frágil as atribuições das equipes, o que gera profissionais inseguros quanto ao seu papel na equipe, assim como os que nós encontramos.

Já a pesquisa de Andrade et al. (2012), realizada no interior de Santa Catarina, aponta uma ausência de açôes de educação permanente e identifica escassas inciativas de capacitação destinadas aos profissionais do NASF.

Segundo o relato dos profissionais, o cenário de desconhecimento e insegurança em relação à proposta do NASF vem se transformado com a realização de espaços de formação, como foi o caso da participação na Oficina de Qualificação do NASF com foco na redução da mortalidade infantil promovida pelo Ministério da Saúde, conforme ilustra a fala a seguir:

a gente estava meio perdido, sem saber pra onde ia, porque quando a gente foi contratado era um negocio meio dúbio. Você faz isso, amanhã você faz aquilo [...] [depois do curso] a gente se norteou melhor e dai a gente teve acho que mais autonomia, até de chegar dentro das unidades de saúde e dizer: a gente faz isso!

Inserido nesse contexto, o terapeuta ocupacional enfrentou também, inicialmente, o desconhecimento da profissão pelos outros profissionais. Assim, utilizaram-se estratégias com a finalidade de esclarecer como o terapeuta ocupacional atua, como e quando pode-se acionar esse profissional; desconstruir concepçōes errôneas sobre a categoria, com explicaçóes sobre o que faz; e acompanhar outros profissionais da equipe, sempre com postura disposta a desenvolver trabalhos em conjunto. É constante a necessidade do profissional de mostrar o que faz, para além do discurso e da teoria. Muitos veem no NASF a possibilidade de revelar o que é a Terapia Ocupacional e em quais áreas pode atuar. Quando solicitados, sentem-se reconhecidos e valorizados.

A gente vem ampliar o olhar assim... bastante. Pela própria profissão, não é? Que é muito rica e atua em muitas áreas, mas ainda existe por parte da população e dos profissionais uma certa dúvida, não é? Eu vejo que assim... a gente está há quase dois anos no NASF, não é? Pelo menos lá onde eu trabalho. Que a gente tem que fazer isso todo dia, de estar todo dia explicando o que é Terapia Ocupacional [...]. Mas é bom ver o reconhecimento, não é? Quando eles começam a compreender o que é a Terapia Ocupacional.

Cavalcante, Tavares e Bezerra (2008) apontam que apesar do avanço conquistado pela Terapia Ocupacional nos últimos anos, caracterizado pela inserçáo do terapeuta ocupacional em novos campos de intervenção, continua existindo na categoria a necessidade de superar o estereótipo da profissão como de baixo status profissional, de aumentar nossa representatividade dentro das equipes de saúde, de promover um maior engajamento político da categoria e aumentar a produçáo científica, tornando-a mais conhecida e valorizada socialmente.

Tais apontamentos também são evidenciados pelos profissionais:

Agora... o que eu vejo assim, a profissão graças a Deus está crescendo bastante, mas o que eu vejo que a Terapia Ocupacional ainda tem pra crescer é na questão de publicação de artigos, de escrever... A gente mostra não só no serviço, ali no dia a dia, mas a gente mostra com pesquisas, com artigos, com publicaçóes pra gente firmar nosso espaço...

Sabemos que essa é uma fragilidade da categoria, que historicamente manteve-se mais articulada ao campo de saberes práticos desenvolvidos nas experiências assistenciais, ancorados na tradição oral do saber-fazer e não formalizados em termos de exigências do discurso científico (MÂNGIA, 1999).

No campo assistencial de atuação do NASF, os profissionais apontam que já começaram a construir uma identidade enquanto equipes de apoio. $\mathrm{O}$ sinal de reconhecimento das EqSF e dos usuários demonstra que, apesar dos obstáculos iniciais, a proposta começa a responder, ainda que com dificuldades, aos seus dois focos de atençáo: as Equipes de Saúde da Família e os usuários do território. 
É... vejo que o nosso trabalho já cresceu muito desde o início, que nós chegamos e agora como nós estamos. [...] A gente não tinha uma identidade como nome e agora nós temos. A comunidade está dando um retorno muito bacana.

As mudanças percebidas pelos terapeutas ocupacionais no seu cotidiano de trabalho nos levam a refletir que existem práticas profissionais na ESF que têm provocado tanto transformaçóes internas, nos próprios profissionais, como externas, no ambiente no qual estáo inseridos, apontando para a existência de uma práxis (VAZQUEZ, 2007) que constrói uma nova realidade da Terapia Ocupacional no contexto da Atenção Primária.

\subsection{Condições de trabalho: um espaço de fragilidades e superação}

Partimos da premissa de que o trabalho humano é sempre mediado, pois no processo de trabalho lança-se mão dos instrumentos ou meios de trabalho adequados os objetivos propostos serem alcançados (VAZQUEZ, 2007). Assim, para a realização do trabalho, os terapeutas ocupacionais no NASF também necessitam de infraestrutura, materiais e equipamentos para que o produto do seu trabalho seja realizado: o cuidado à saúde.

$\mathrm{O}$ acesso aos materiais necessários para a realização das açôes cotidianas de trabalho dos terapeutas ocupacionais foi colocado como um grande obstáculo. Segundo eles, no processo de implantação do NASF os profissionais foram informados de que receberiam materiais específicos para atuação, inclusive foram solicitadas listas de cada categoria profissional apontando as necessidades. Contudo, a burocracia e o atraso na entrega, além da qualidade do material, inviabilizam as práticas profissionais.

A escassez de material e as condições de trabalho precárias são também evidenciadas em outros estudos sobre o trabalho de terapeutas ocupacionais, como o de Ho e Oliver (2005), que estudaram a inserção de terapeutas ocupacionais do sistema público do município de São Paulo, SP; e o de Bezerra, Tavares e Cavalcante (2009), que objetivou conhecer o mercado de trabalho da Terapia Ocupacional em Maceió, AL.

Outra questáo refere-se à ausência/insuficiência de veículos para o deslocamento das equipes (para a realização de visitas domiciliares e atividades externas na comunidade) e a insegurança percebida a partir da óptica da violência nas comunidades.
Bezerra, Tavares e Cavalcante (2009, p. 80) assinalam que para compreender a falta de recursos materiais e financeiros, além da estrutura física inadequada, devem-se reportar aos reflexos do processo de reforma do Estado, onde há uma minimizaçáo referente aos gastos sociais, o que vem interferir no repasse dos recursos necessários para o desempenho das atividades profissionais no setor público.

Nesse sentido, vale ressaltar que o setor da Saúde não está à margem das transformaçôes do mundo do trabalho e que esse contexto de precarização influencia diretamente os processos de trabalho dos profissionais de Saúde e, por consequência, o produto do seu trabalho. Lembrando que o processo terapêutico deve ter por princípio, segundo Francisco (2001), ser o lugar onde, por meio do fazer (atos, açóes, atividades), o usuário percebe-se como sujeito que cria, atua, reconhece, organiza e gerencia o seu cotidiano concreto.

Um lugar onde a convivência com as contradiçóes vividas pelas suas açôes cotidianas possa ser trazida para o fazer concreto - no manuseio de diferentes materiais/atividades/ situaçóes -, abrindo assim a possibilidade de reconhecimento e enfrentamento de suas dificuldades cotidianas, na busca por um enriquecimento de suas necessidades e possibilidades concretas, no interior da coletividade. (FRANCISCO, 2001, p. 66, grifos nossos).

Considerando as dificuldades, os terapeutas ocupacionais adotaram estratégias para minimizar a interferência das condiçóes de trabalho na sua atuação profissional. Utilizaram criatividade e improviso, recolheram materiais recicláveis na comunidade e chegaram a financiar a compra de materiais e mobiliário em busca de resolutividade. Contudo, mesmo praticando, muitos são contrários a essa estratégia e alegam que tal prática oculta a fragilidade do financiamento e das condiçóes no setor da Saúde.

\section{E ai a gente vai buscando as alternativas de material que vai encontrando, da comunidade. [...] Os agentes de saúde falam lá pra comunidade e todo mundo traz.}

A arrecadação de recursos, o uso da criatividade/ improviso/sensibilidade, bem como a doação de material como estratégia de superação das dificuldades objetivas nos ambientes de trabalho, são realidades comuns retratadas em outros estudos (HO; OLIVER, 2005; BEZERRA; TAVARES; CAVALCANTE, 2009). Tais situações demonstram que os profissionais 
ainda possuem uma visão ingênua de que a vontade e os propósitos individuais, apenas, fossem suficientes para atender as necessidades dos usuários.

Nesse contexto, uma verdadeira ação transformadora da Terapia Ocupacional exige uma reflexão crítica sobre as condições de trabalho, bem como um movimento de exigência, para que materiais e equipamentos sejam adquiridos com recursos destinados a esse fim.

A importância do engajamento dos profissionais e a apropriação acerca da cogestão da política do NASF no município foram apontamentos importantes surgidos a partir da discussão da realidade de trabalho dos participantes. Andrade et al. (2012) apontam em seu estudo a necessidade de os profissionais se envolverem com os mecanismos de gestáo como forma de exercitar o diálogo e garantir um planejamento mais realista e autônomo para a tomada de decisôes.

Diante dessa situação, os participantes apontaram a necessidade de organização dos profissionais do NASF em favor da luta por melhores condiçóes de trabalho. Contudo, ao pensar nessas estratégias, esbarraram em mais um obstáculo: a fragilidade do vínculo ao qual estão submetidos e a instabilidade da política.

Eu acho que falta ter essa unidade e cobrar, gente! [...] Será que pela instabilidade o pessoal tem medo? Esse questionamento, de cobrar... Essa cobrança de dinheiro... eu fico pensando se é por conta dessa instabilidade. Ninguém sabe do NASF, a continuidade, não é?

Essa discussão remete tanto ao fato de o NASF ser regulado por uma portaria quanto à forma de contratação dos profissionais do NASF, que se dá por meio de organização social de saúde (OSS), o que caracteriza uma forma de terceirização em detrimento da vinculação via concurso público, como deveria acontecer com as contratações pelo setor público, garantindo estabilidade aos trabalhadores.

A terceirização "[...] caracteriza-se como uma técnica de administração através da qual se interpóe um terceiro, geralmente uma empresa, na relação típica de trabalho (empregado versus empregador)." (CHERCHGLIA, 1999, p. 368).

As OSS também estão presentes na gestão dos serviços públicos em São Paulo e também são responsáveis pela contratação dos trabalhadores do NASF. Segundo Lancman e Barros (2011, p. 266):

Essa forma de gestáo termina mesclando o caráter público e privado dos serviços oferecidos, criando situaçôes de trabalho heterogêneas a depender da parceira envolvida. Essa heterogeneidade de práticas profissionais nas diferentes regióes da cidade pode dificultar a criação de uma cultura comum entre as várias equipes, comprometendo a troca de experiências e a consolidação das políticas públicas.

Tal forma de contratação fragiliza cada vez mais o trabalho em Saúde, principalmente a atuação na Saúde da Família. Ela aumenta a rotatividade entre os profissionais, por conta da instabilidade, o que compromete o vínculo entre profissional e usuário e, no caso do NASF, apoiador e apoiado. Além disso, estabelece uma polarização entre os trabalhadores estáveis e os instáveis, dificultando a unificação entre os trabalhadores da Saúde, como podemos evidenciar na fala abaixo:

E olha só... numa das reuniōes que a gente fez, de explanação e explicação [...] um médico levantou a mão e eu, crente que ele ia perguntar alguma coisa em relação a isso, e disse: Mas me diga uma coisa, vocês sáo concursados? Como foi que vocês chegaram aqui?

Diante desse cenário, os trabalhadores perdem de vista o caráter coletivo do seu papel e passam a realizar negociaçôes e reivindicações de forma localizada e até mesmo individualizada, provocando assim a fragmentação e a desmobilização dos trabalhadores. Nesse sentido, Bezerra, Tavares e Cavalcante (2009) apontam que o terapeuta ocupacional necessita exercer uma prática politizada não restrita à ação técnica, e que essa seja capaz de reconhecer não apenas as demandas dos usuários, mas também as contradiçóes sociais no âmbito da instituição para, a partir disso, buscar formas de garantir direitos, no sentido de ampliar o atendimento e buscar melhores condiçôes de trabalho para dar respostas qualificadas aos usuários.

O processo de terceirização no setor da Saúde, no Brasil, tem implicaçóes para além de seu aspecto gerencial. As terceirizaçóes influenciam diretamente o processo de trabalho e assim afetam a subjetividade do trabalhador; no mínimo, elas geram desconforto por conta do paradoxo existente entre autonomia profissional e risco de demissão.

Porque não dá pra gente sempre estar tirando do bolso da gente. E injusto [...] Às vezes a gente fica até desmotivado. Se desmotiva bastante. Nessa reunião [com a gestão] a gente falou. $O$ pessoal da nossa equipe falou que a gente não tava tendo carro. [...] [profissional pergunta] $O$ que fazer com as pessoas que estão necessitadas? "Não tem carro, não faz. Tá necessitada? Não pode se fazer nada." Isso foram palavras não minhas, mas da pessoa na reuniäo... 
A necessidade de unificação do trabalho do NASF para que os núcleos possam ter uma identidade comum também é colocada como um desafio. Podemos compreender que a necessidade levantada não se refere à "padronização das açôes", mas sim de que os NASF da cidade possam compreender as singularidades existentes em cada território e ainda assim "agir em sintonia”. Dessa forma, os núcleos realizariam açóes diferentes, mas com a compreensão de um objetivo em comum, que é responder às necessidades das equipes e dos usuários enquanto núcleo de apoiadores.

\section{Considerações finais}

O estudo possibilitou acessar um universo novo e ainda pouco conhecido sobre as iniciativas e estratégias do terapeuta ocupacional nos Núcleos de Apoio à Saúde da Família. O caráter exploratório da pesquisa permitiu conhecer, a partir da óptica dos próprios profissionais, suas perspectivas com relação à inserção da categoria na Estratégia Saúde da Família.

A realidade dos trabalhadores foi evidenciada, demostrando as fragilidades no trato do trabalhador da Saúde no serviço público, bem como as dificuldades de implementaçáo de uma política em construção. Ressalta-se que essa realidade não é distinta nos demais estudos realizados nos estados brasileiros, evidenciando que as contingências que interferem na construção da proposta não são necessariamente advindas do contexto local.

Pôde-se perceber a importância do encontro como espaço potencializador de reflexôes sobre os processos de trabalho, de trocas de experiências e conjeturas críticas que acrescentaram consciência e sensibilização aos terapeutas ocupacionais, no sentido de avançar e buscar novas perspectivas profissionais enquanto trabalhadores da Saúde na Atenção Primária. O estudo motivou o aprofundamento dessas questões, tanto no campo técnico-assistencial quanto no político, a fim de despertar novas iniciativas de publicizaçấo da atuação dos terapeutas ocupacionais nesse contexto.

Considera-se a necessidade de realização de pesquisas sobre a Terapia Ocupacional na Atenção Primária à Saúde, com vistas à consolidação de saberes e práticas, e se aponta a necessidade de tornar a política aberta à construção dos atores envolvidos, de forma a reduzir o seu caráter verticalizado e de forma a somar esforços em torno da qualificação dessa política que envolve a importância de formação e valorização dos profissionais inseridos nessa nova proposta.

\section{Referências}

ANDRADE, L. M. B. D. et al. Análise da implantação dos Núcleos de Apoio à Saúde da Família no interior de Santa Catarina. Saúde e Transformação Social, Florianópolis, v. 3, n. 1, p. 18-31, 2012.

BARROS, D. D.; LOPES, R. E.; GALHEIGO, S. M. Terapia Ocupacional Social: concepçôes e perspectivas. In: CAVALCANTI, A.; GALVÃO, C. (Org.). Terapia Ocupacional: Fundamentação \& Prática. Rio de Janeiro: Guanabara Koogan, 2007. p. 347-353.

BARROS, D. D.; GHIRARDI, M. I. G.; LOPES, R. E. Terapia Ocupacional e sociedade. Revista de Terapia Ocupacional da USP, São Paulo, v. 10, n. 2-3, p. 69-74, maio/dez. 1999.

BEIRÃO, R. O. S.; ALVES, C. K. A. Terapia Ocupacional no SUS: refletindo sobre a normatização vigente. Cadernos de Terapia Ocupacional da UFSCAR, São Carlos, v. 18, n. 3, p. 231-246, set./dez. 2010.

BEZERRA, W. C.; TAVARES, M. M. F.; CAVALCANTE, G. M. M. C. O mercado de trabalho da terapia ocupacional em Maceió-AL no contexto contemporâneo de crise do capital. Revista de Terapia Ocupacional da USP, São Paulo, v. 20, n. 2, p. 75-84, maio/ago. 2009.

BRASIL. Ministério da Saúde. Conselho Nacional de Saúde. Resolução no 196, de 10 de outubro de 1996. Estabelece as diretrizes e normas regulamentadoras de pesquisas envolvendo seres humanos. Diário Oficial da República Federativa do Brasil, Brasília, DF, Poder Executivo, Brasília, DF, 16 out. 1996. Seção 1.

BRASIL. Ministério da Saúde. Portaria no 154, de 24 de janeiro de 2008. Cria os Núcleos de Apoio à Saúde da Família - NASF. Diário Oficial da República Federativa do Brasil, Brasília, DF, 04 mar. 2008. Seção 1, n. 43. Disponível em: <http://dtr2004.saude.gov.br/dab/nasf. php>. Acesso em: 10 abr. 2010.

BRASIL. Ministério da Saúde. Secretaria de Atenção à Saúde. Departamento de Atenção Básica. Diretrizes do NASF. Brasília: Ministério da Saúde, 2009. (Cadernos de Atençáo Básica, n. 27, série B, Textos Básicos de Saúde).

BRASIL. Ministério da Saúde. Cadastro Nacional dos Estabelecimentos de Saúde do Brasil - CNES. Arquivo com Profissionais em mais de uma equipe por UF/ na competência 05/2011. Brasília: Ministério da Saúde, 2011a. Disponível em: <http://cnes.datasus.gov. br/Mod_Ind_Equipes.asp?VEstado=23\&VMun=23044 0\&VComp=201106>. Acesso em: 03 jul. 2011.

BRASIL. Ministério da Saúde. Portaria no 2.488, de 21 de abril de 2011. Aprova a Política Nacional de Atenção Básica, estabelecendo a revisão de diretrizes e normas para a organização da Atenção Básica, para a Estratégia Saúde da Família (ESF) e o Programa de Agentes Comunitários de Saúde (PACS). Diário Oficial da República Federativa do Brasil, Brasília, DF, 22 abr. 2011b. Seção 1, n. 43.

CAMPOS, G. W. S. Equipes de referência e apoio matricial: uma proposta de reorganização do Trabalho em saúde. Ciência e Saúde Coletiva, Rio de Janeiro, v. 4, n. 2, p. 393-404, 1999.

CAVALCANTE, G. M. M.; TAVARES, M. M. F.; BEZERRA, W. C. Terapia ocupacional e capitalismo. 
Revista de Terapia Ocupacional da USP, São Paulo, v. 19, n. 1, p. 29-33, jan./abr. 2008.

CHERCHGLIA, M. L. Terceirização do Trabalho nos serviços de saúde: alguns aspectos conceituais, legais e pragmáticos. In: SANTANA, J. P.; CASTRO, J. L. (Org.). Capacitação em Desenvolvimento de Recursos Humanos de Saúde. Natal: Ed. UFRN, 1999. p. 367-385.

FORTALEZA. Secretaria Municipal de Saúde - SMS. SMS promove curso para profissionais do NASF. Fortaleza: SMS, ago. 2009. Notícias. Disponível em: <http://www. sms.fortaleza.ce.gov.br/sms_v2/Noticias_Detalhes. asp?noticia $=1626>$. Acesso em: 24 mar. 2010.

FRANCISCO, B. R. Terapia Ocupacional. Campinas: Papirus, 2001.

FRANCO T. B.; MERHY, E. E. PSF: contradiçóes de um programa destinado à mudança do modelo assistencial. In: MEHY, E. E. et al. (Org.). O trabalho em saúde: olhando e experienciando o SUS no cotidiano. São Paulo: Editora Hucitec; 2003. p. 55-124.

FROTA, A. C. O processo de trabalho na Estratégia de Saúde da Família: o caso Fortaleza. 2008. 112 f. Dissertação (Mestrado Profissional em Vigilância em Saúde)-Escola Nacional de Saúde Pública Sergio Arouca, Fundação Oswaldo Cruz, Fortaleza, 2008.

GOMES, V. L. O.; TElles, K. S., ROBAllO, E. C. Grupo focal e discurso do sujeito coletivo: produção de conhecimento em saúde de adolescentes. Escola Anna Nery, Rio de Janeiro, v. 13, n. 4, p. 856-862, 2009. http://dx.doi.org/10.1590/S1414-81452009000400023

HO, D. C.; OLIVER, F. C. Terapia Ocupacional e saúde da pessoa com deficiência na Secretaria Municipal de Saúde:uma discussão sobre dez anos de sua incorporação. Revista de Terapia Ocupacional da USP, São Paulo, v. 16, n. 3, p. 114-123, 2005.

INSTITUTO BRASILEIRO DE GEOGRAFIA E ESTATÍSTICA - IBGE. Resultados censo 2010. Rio de Janeiro: IBGE, 2010. Disponível em: <http://www.ibge. gov.br/home/estatistica/populacao/censo2010/tabelas_pdf/ total_populacao_ceara.pdf >. Acesso em: 09 set. 2011.

JARDIM, T. A.; AFONSO, V. C.; PIRES, I. C. A terapia ocupacional na Estratégia de Saúde da Família-evidências de um estudo de caso no município de São Paulo. Revista de Terapia Ocupacional da USP, São Paulo, v. 19, n. 3, p. 167-175, 2008.

JORGE, R. C. Entrevista com o Prof. Rui Chamone. Cadernos de Terapia Ocupacional, Belo Horizonte, v. 16, n. 1, p. 15-28, 2004.

LANCMAN, S.; BARROS, J. O. Estratégia de saúde da família (ESF), Núcleo de Apoio à Saúde da Família
(NASF) e terapia ocupacional: problematizando as interfaces. Revista de Terapia Ocupacional da USP, São Paulo, v. 22, n. 3, p. 263-269, set./dez. 2011.

MALFITANO, A. P. S.; FERREIRA, A. P. Saúde pública e terapia ocupacional: apontamentos sobre relações históricas e atuais. Revista de Terapia Ocupacional da USP, Sáo Paulo, v. 22, n. 2, p. 102-109, maio/ago. 2011.

MÂNGIA, E. F. Terapia Ocupacional: práticas, discursos e a questão da legitimidade científica. Revista de Terapia Ocupacional da USP, São Paulo, v. 10, n. 2-3, p. 55-59, maio/dez. 1999.

MARX, K.; ENGELS, F. Trabalho assalariado $e$ capital. 4. ed. Sáo Paulo: Global, 1987.

MERCADO, F. J.; BOSI, M. L. M. Introdução: notas para um debate. In: BOSI, M. L. M.; MERCADO, F. J. Pesquisa qualitativa de serviços de saúde. Petrópolis: Vozes, 2004. p. 23-71.

MERHY, E. E. A perda da dimensão cuidadora na produção da saúde - Uma discussão do modelo assistencial e da intervençáo no seu modo de trabalhar a assistência. In: CAMPOS, C. R. et al. Sistema Único de Saúde em Belo Horizonte - reescrevendo o público. Belo Horizonte: Xamã/VM Ed., 1998. p. 103-120.

MINAYO, M. C. S. O desafio do conhecimento: pesquisa qualitativa em Saúde. São Paulo: Hucitec; Rio de Janeiro: ABRASCO, 2004.

OLIVER, F. C.; BARROS, D. D.; LOPES, R. E. Estudo sobre a incorporação da terapia ocupacional no contexto das açôes de saúde mental e saúde da pessoa com deficiência no Município de São Paulo entre 1989 e 1993. Revista de Terapia Ocupacional da USP, São Paulo, v. 16, n. 1, p. 31-39, 2005.

PAIM, J. S. Modelos de atenção e vigilância da saúde. In: ROUQUAYROL, M. Z.; ALMEIDA FILHO, N. (Org.). Epidemiologia e saúde. 6. ed. Rio de Janeiro: MEDSI, 2003. p. 567-586.

PAIM, J. S. Determinantes sociais de saúde. In: SEMINÁRIO SOBRE A POLÍTICA NACIONAL DE PROMOÇÃO DA SAÚDE, 1., 2009, Brasília. Anais... Brasília: Ministério da saúde, 2009. p. 29- 37.

VAZQUEZ, A. S. Filosofia da Práxis. São Paulo: Expressão Popular, 2007.

WORLD FEDERATION OF OCCUPATIONAL THERAPISTS - WFOT. Definiçöes de terapia ocupacional. Forrestfield: WFOT, 2003. Apoio: Faculdades Salesianas de Lins, CETO/SP, ABRATO.

\section{Contribuição dos Autores}

Fernanda Reis participou da concepção e redação do texto e Ana Cléa Veras Camurça Viera auxiliou no processo de análise e revisão final do texto. 